\section{Estudo compreensivo sobre suicídio de mulheres idosas de sete cidades brasileiras}

\author{
A comprehensive study on suicide among older \\ women in seven Brazilian cities
}

\author{
Estudio comprensivo sobre suicidio de mujeres \\ mayores en siete ciudades brasileñas
}

\author{
${ }_{1}$ Escola Nacional de Saúde \\ Pública Sergio Arouca \\ Fundação Oswaldo Cruz, Rio \\ de Janeiro, Brasil. \\ 2 Universidade Veiga de \\ Almeida, Rio de Janeiro, \\ Brasil. \\ Correspondência \\ M. C. S. Minayo \\ Centro Latino-Americano de \\ Estudos de Violência e Saúde \\ Jorge Careli, Escola Nacional \\ de Saúde Pública Sergio \\ Arouca, Fundação Oswaldo \\ Cruz. \\ Av. Brasil 4036, sala 700, \\ Rio de Janeiro, RJ \\ 21040-361, Brasil. \\ cecilia@claves.fiocruz.br
}

\begin{abstract}
This article is based on a multicenter study in Brazil, analyzing 51 cases of suicide in elderly individuals (40 men and 11 women) based on psychosocial autopsies. A more in-depth study was conducted on the 11 cases in women. Data interpretation was based on classical authors and the recent national and international literature on the phenomenon. Women's motives for committing suicide differed partially from those of men. Like men, women committed suicide mainly by hanging themselves, and their suicide was frequently associated with degenerative illnesses and comorbidities. The main differences were due to cultural gender issues. The results agree largely with the literature and show that in Brazil the main factors associated with suicide in women are: gender and intra-family violence, suffering due to loss of significant others and the traditional role of wife and mother, and depression. The study highlights the importance of greater attention to the cumulative effect of problems with aging in women, especially those related to gender specificities.
\end{abstract}

Suicide; Gender Identity; Women; Aged
Maria Cecília de Souza Minayo ${ }^{1}$ Fatima Gonçalves Cavalcante 2

\section{Resumo}

Parte-se de uma pesquisa multicêntrica realizada no Brasil, em que se analisam 51 casos de suicídio de idosos (de 40 homens e 11 mulheres) mediante autópsias psicossociais. Aprofunda-se o estudo dos 11 casos relativos às mulheres. A interpretação dos dados empíricos se fundamenta em autores clássicos e em recente literatura nacional e internacional sobre o fenômeno. Motivos que levam as mulheres ao suicídio são, em parte, diferentes dos homens. Como eles, as mulheres morrem preferencialmente por enforcamento e frequentemente seu suicídio associa-se a doenças degenerativas e comorbidades. As diferenças principais se devem a questões culturais de gênero. Os resultados convergem em grande parte com a literatura e revelam que, no Brasil, os fatores principais associados ao suicídio feminino são: violência de gênero e intrafamiliar, sofrimento por perdas de pessoas referenciais e da função tradicional como esposa e mãe, e depressão. Recomenda-se maior atenção ao efeito cumulativo de agravos no envelhecimento das mulheres, sobretudo os vinculados às especificidades de gênero.

Suicídio; Identidade de Gênero; Mulheres; Idoso 


\section{Introdução}

Suicídio é um ato deliberado de infligir a morte a si próprio. Os riscos para esse tipo de morte incluem fatores biológicos, psicológicos, médicos e sociais, segundo a Organização Mundial da Saúde 1 .

Este artigo trata especificamente e do ponto de vista qualitativo do suicídio consumado de mulheres idosas, cujos dados foram recolhidos por meio de "autópsias psicossociais". O estudo se vale da hipótese de que os motivos utilizados pelas mulheres para dar fim a sua vida são, em parte, diferentes dos apresentados pelos homens. Pesam sobre essas diferenças questões culturais de gênero que se expressam no que se costuma chamar "condição feminina”. Pensamentos de autores que trazem uma visão tradicional sobre gênero e suicídio 2,3,4 serão contrastados com a visão de alguns que apresentam uma ótica pós-estrutural e culturalista 5,6,7,8,9. Embora gênero seja um dos mais importantes fatores preditivos de suicídio na velhice, geralmente o tema costuma ser tratado predominantemente como constatação estatística $10,11,12,13,14$ e, secundariamente, do ponto de vista de seu significado 5,6,7,8,9,15.

Estudos compreensivos especificamente sobre suicídio de mulheres - especialmente de mulheres idosas - são escassos na literatura mundial $4,8,9,15$, uma vez que elas se matam menos que os homens, numa proporção que varia de 1:4 e nunca menos de 1:2 1,10,11,12,13,14,15,16, a não ser em alguns países como a China e a Índia 17 em que as taxas são semelhantes entre os sexos. No Brasil, no ano de 2009, por exemplo, houve uma média de 5.8/100 mil suicídios para a população em geral e de 9,0/100 mil para a população idosa. Os homens apresentam as taxas mais elevadas nesse grupo etário. De acordo com as regiões, elas oscilaram entre 8,7/100 mil e 15.4/100 mil para homens de 60 anos ou mais, enquanto as relativas às idosas estão estabilizadas entre 2,4/ 100 mil e 2,6/100 mil 16. As literaturas brasileira $16 \mathrm{e}$ internacional 1,10,11,12,13,14,15 mostram também que entre os homens mais velhos existe tendência de crescimento das taxas de suicídio em quase todo o mundo. É igualmente conhecido que, na maioria dos países, as mulheres idosas fazem mais tentativas de se matar que os homens $1,3,4,5$, $6,9,10,11,12,13,14,15,16,17,18$.

Em geral, os autores que tratam da relação entre gênero e suicídio na velhice não fazem distinção das características de comportamentos suicidas entre os sexos ou dão mais ênfase às dos homens, sublinhando, sobretudo, a associação com isolamento social, perdas de estado profissional, desvantagens financeiras e relacionais depois da aposentadoria, dificuldades para aceitar as contingências da velhice e ocorrência de doenças, particularmente as que afetam a honra e a virilidade 5,6,7,11,12,18. Já no caso das mulheres, alguns textos explicam de forma machista $\mathrm{e}$ discriminatória sua menor vulnerabilidade para praticar o suicídio. Por exemplo, Durkheim, em seu clássico trabalho sobre suicídio ao final do século XIX, comenta que essa diferença entre os sexos se deve ao fato de a mulher ter uma sensibilidade mais rudimentar e uma vida mental menos desenvolvida, ter menos aspirações e necessidades e de se satisfazer com mais facilidade. Em pleno século XX, Lester 3 adotou a mesma explicação, dizendo que a pouca força física da mulher a impediria de utilizar uma arma de fogo ou qualquer outro meio mais agressivo para se matar. É também o pensamento de Neuringer ${ }^{4}$ para quem a mulher escapa da morte autoinfligida porque é mais passiva, inepta, e não tem pensamento lógico para realizar tal ato de forma eficiente.

Como se constata, parte da ciência da suicidologia incorporou os mesmos preconceitos de gênero que marcaram época na ciência ocidental dentro de uma visão patriarcalista cuja vigência é secular e ainda encontra adeptos quanto à ideia de inferioridade e de desvantagem de atributos e papéis da mulher. Em seu livro O Segundo Sexo, Simone de Beauvoir 19 (p. 58) evidenciou o quanto a ciência e a cultura contribuíram para a reprodução desse machismo, com a cumplicidade da própria mulher: "que se submete voluntariamente, criando de si a imagem de um ser humano frágil, infantilizado, intelectualmente incapaz, pernicioso e perigoso". A forma como a questão de gênero tem sido tradicionalmente tratada se reflete também na visão do envelhecimento feminino, pois como lembra Simone de Beauvoir em La Vieillesse 20, uma mulher velha, em várias sociedades significa ser uma pessoa assexuada e tradicionalmente associada a bruxarias e ao apagamento social.

Apesar de serem referências minoritárias, alguns autores aprofundam especificamente a questão do suicídio feminino, como é o caso de Beautrais 15 para quem a mulher é mais propensa ao suicídio que o homem. Esse autor, numa revisão de literatura, encontrou uma série de fatores que contribuem para o comportamento suicida feminino: maior prevalência de depressão, ideação e tentativas de autoextermínio; maior ocorrência de distúrbios alimentares; psicose pós-parto; grande ocorrência de ideação suicida após aborto induzido e nas situações de baixos níveis de estrogênio e serotonina; grande vulnerabilidade à perda de filhos; violência doméstica contra elas e os filhos. 
Outros autores, ao contrário, vêm ressaltando um lado positivo da antropologia feminina que ajudaria as mulheres a cometerem menos suicídio que os homens - inclusive as mulheres idosas -, mostrando que elas, em geral, são mais resistentes e vivem mais que os homens (no Brasil, a diferença é de oito anos); envolvem-se menos que eles em estilos de vida destrutivos como abuso de drogas lícitas e ilícitas, direção perigosa, brigas e homicídios; agem menos por impulso; constroem laços afetivos e redes sociais mais facilmente; têm um pensamento mais inclusivo e complexo; aliam razão e emoção; cultivam várias prioridades na vida e não são movidas apenas por objetivos profissionais; são mais envolvidas com a família e a comunidade 5,8,9.

Essas vantagens comparativas do modo feminino de estar no mundo produziriam, segundo várias autoras 21,22,23,24,25, uma ética de cuidado, de interação, de convívio e de afeto, baseada num pensamento concreto que passa pelo corpo, é complexo e holístico. Obviamente, tal diferencial não seria fruto da natureza feminina e, sim, da socialização.

Este artigo não se detém apenas nas diferenças de gênero. Busca compreender empiricamente os casos e as múltiplas razões de 11 mulheres que faleceram por suicídio e cujos fragmentos de histórias pessoais que as levaram à morte autoinfligida, narradas por seus familiares, são descritas e interpretadas a seguir.

\section{Metodologia}

Apresenta-se o resultado de um estudo com familiares de 11 idosas que morreram por suicídio. Os dados fazem parte de uma investigação multicêntrica de cunho qualitativo e quantitativo realizada entre 2010 e 2012. As fontes de informação para seleção da amostra foram os bancos oficiais sobre mortalidade, laudos periciais, registros de óbito em cartório, registros hospitalares e informações de profissionais que atuam no Sistema Único de Saúde de dez municípios brasileiros das cinco regiões do país: Manaus (Amazonas), Teresina (Piauí), Fortaleza e Tauá (Ceará), Campo Grande e Dourados (Mato Grosso do Sul), Campos dos Goytacazes (Rio de Janeiro), São Lourenço do Sul, Candelária e Venâncio Aires (Rio Grande do Sul). A seleção dos casos para realização das autópsias psicológicas e psicossociais 26 levou em conta o intervalo de dois a cinco anos retroativos (2006 a 2010). Não existe consenso entre os estudiosos sobre esse tempo, pois alguns autores advogam que o sofrimento pós-traumático que acompanha os eventos por suicídio deixa registrados na memória afetiva e social, ao longo de muitos anos, os fatos testemunhados 6 . Outros como Conner et al. 27, numa revisão atual sobre o assunto, no entanto, propõem que esse intervalo não deva ser superior a um ano, com o intuito de se evitar o viés de memória dos informantes.

O principal instrumento de pesquisa foi a técnica de autópsia psicossocial, um tipo de entrevista semiestruturada 6,26,28,29, que integra aspectos socioantropológicos à análise dos estados emocionais da pessoa que morreu por suicídio. A caracterização dessas mulheres levou em conta sua história e modo de vida; avaliação dos antecedentes e da atmosfera do ato de se matar; impacto na família; letalidade do método; proximidade de fontes de apoio; intenção já manifestada do desejo de se suicidar; estado mental que antecedeu o ato; imagem e reações da família e da comunidade.

$\mathrm{Na}$ análise do material, buscou-se compreender as peculiaridades das mortes dessas mulheres em seus ambientes socioculturais. Trabalhou-se com uma abordagem que levou em consideração o relato dos familiares ou pessoas próximas, os dados de contextualização do lugar dessa idosa na família e as peculiaridades de sua condição feminina.

O projeto de pesquisa que deu origem a este texto foi aprovado pelo Comitê de Ética em Pesquisa da Fundação Oswaldo Cruz. As recomendações éticas foram respeitadas e familiares em crise, encaminhados e acompanhados em serviços de referência.

\section{Resultados}

Para contextualizar o fenômeno do suicídio das mulheres no Brasil, apresenta-se (Figura 1) uma série histórica que mostra a estabilidade dos dados referentes a elas, tendo em conta todas as idades e em comparação com as taxas muito mais elevadas e flutuantes dos homens, cujo pico foi em 2005, mostrando tendência de decréscimo a partir de então. Como se pode observar, as duas linhas referentes às mulheres estão situadas num patamar muito baixo se comparado às médias para o país e para os homens, o que constata o sexo masculino como grupo de maior risco para a morte autoinfligida.

A seguir, apresenta-se breve caracterização das mulheres que faleceram por suicídio, e cujos eventos são aqui analisados (Tabela 1).

Os casos se distribuem por sete municípios e as idades, separadas por segmento, compreendem cinco casos na faixa de 60-69, quatro entre 70-79 e dois, acima de 80 anos. Para preservar as identidades, foram usados nomes de flores para nomear as mulheres. A maioria delas tinha for- 
Figura 1

Coeficientes de mortalidade por suicídio segundo sexo e faixa etária (10-59 anos e 60 anos ou mais). Brasil, $1980-2009$.

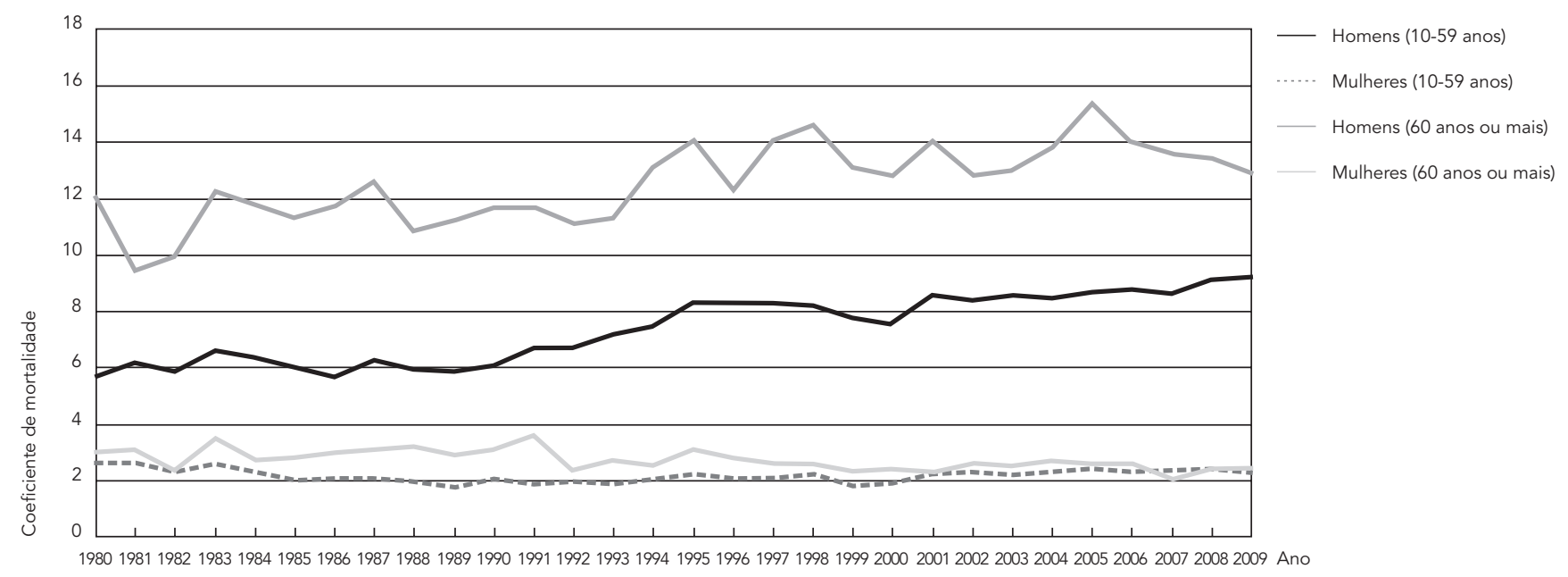

Fonte: Sistema de Informações sobre Mortalidade, Departamento de Informática do SUS, Ministério da Saúde.

Tabela 1

Caracterização das 11 mulheres que faleceram por suicídio segundo local de moradia, sexo, idade, estado civil, profissão e meio utilizado.

\begin{tabular}{|c|c|c|c|c|c|c|}
\hline Nome & Lugar de moradia & Idade & Grau de instrução & Estado civil & Profissão & Meio de suicídio \\
\hline Hortência & Campo Grande & 61 & $\begin{array}{l}\text { Ensino Fundamental } \\
\text { incompleto }\end{array}$ & Viúva & Do lar & Enforcamento \\
\hline Orquídea & Candelária & 62 & Ensino Fundamental & Viúva & Agricultora/Do lar & Enforcamento \\
\hline Acácia & Teresina & 64 & Superior & Viúva & Dentista & Queda de altura \\
\hline Exótica & $\begin{array}{l}\text { São Lourenço } \\
\text { do Sul }\end{array}$ & 65 & $\begin{array}{l}\text { Ensino Fundamental } \\
\text { incompleto }\end{array}$ & Viúva & Agricultora/Do lar & Enforcamento \\
\hline Sépala & Dourados & 67 & $\begin{array}{l}\text { Ensino Fundamental } \\
\text { incompleto }\end{array}$ & Viúva & Do lar & Enforcamento \\
\hline Violeta & Candelária & 71 & Analfabeta & Viúva & Agricultora/Do lar & Enforcamento \\
\hline Estrelícia & $\begin{array}{l}\text { São Lourenço } \\
\text { do Sul }\end{array}$ & 72 & $\begin{array}{l}\text { Ensino Fundamental } \\
\text { incompleto }\end{array}$ & Viúva & Agricultora/Do lar & Enforcamento \\
\hline Margarida & Teresina & 72 & Superior & Solteira & Funcionária pública & Chamas \\
\hline Iris & Dourados & 75 & Ensino Fundamental & Viúva & Do lar & Enforcamento \\
\hline Camélia & Venâncio Aires & 82 & $\begin{array}{c}\text { Ensino Fundamental } \\
\text { incompleto }\end{array}$ & Viúva & Agricultora/Do lar & Enforcamento \\
\hline Rosa & $\begin{array}{l}\text { Campos dos } \\
\text { Goytacazes }\end{array}$ & 82 & $\begin{array}{l}\text { Ensino Fundamental } \\
\text { incompleto }\end{array}$ & Separada & Do lar & Chamas \\
\hline
\end{tabular}

mação escolar Ensino Fundamental incompleto e completo (oito), duas possuíam nível Superior e uma era analfabeta. Nove das 11 eram viúvas, havia uma solteira e uma separada. Quatro mu- lheres exerciam apenas funções domésticas e cinco, além dessas, eram agricultoras. Só duas tinham profissões de nível Superior, uma numa repartição pública, e outra como dentista. A maio- 
ria (oito) usou como meio para tirar a própria vida o enforcamento e das três que utilizaram outros métodos (carbonização parcial por chamas e queda de altura), todas viviam em cidades grandes.

Realizou-se uma análise que enfatiza o que há de comum nesse conjunto de histórias e, em seguida, verificaram-se as associações entre depressão e morte. O desafio foi mostrar várias faces de um problema multicausal e a relevância das características concomitantes que se associam a ele.

Há de comum nesse grupo de mulheres cinco pontos fundamentais: o impacto da violência no curso da vida; problemas vinculados à dinâmica familiar; efeitos de comorbidades; associação com vários tipos de depressão e associação com perdas e luto por causa de pessoas referenciais.

\section{Impactos da violência no curso da vida}

A violência na infância, intrafamiliar e de gênero deixaram marcas e há estudos que demonstram a associação entre violência e suicídio 6,11,12. Internalizada, a violência mina forças psíquicas como pulsão, e sem mediação interfere nas relações interpessoais e sociais e realimenta traumas. As marcas dessas vivências podem suscitar ideias e consumação de suicídios. Severos maus-tratos associados a outros problemas afetaram quatro idosas.

Dona Sépala, maltratada pelos pais e vítima de trabalho escravo na infância, tinha traumas inesquecíveis. Embora grata pelos quatro filhos que teve e pelos 47 anos de vida conjugal, dizia ao final (nas palavras de sua filha): "eu já fiz tudo o que tinha que fazer aqui na terra, estou pronta para ir". "Ela foi deprimida a vida toda como dois de seus onze irmãos", contou a filha.

Dona Exótica sofreu maus-tratos do pai violento e alcoolista, na relação conjugal com o marido e a reproduziu com os sete filhos que assim a descreveram: " a mãe reagia quase na mesma moeda. Se fosse para brigar, ela brigava; se tivesse que pegar uma faca ela pegava. Se mexesse com o ninho ela defendia. Ela tinha a boca suja". Essa "agricultora transtornada", como a chamavam, era vista como agressiva, violenta e brigona com filhos, noras e vizinhos.

Dona Rosa testemunhou seu marido assassinar a foice um empregado, a tentativa de assassinato da filha pelo genro, o que a deixou paraplégica, o suicídio desse genro e a morte por afogamento de um filho. Convivia também com um filho com severos transtornos mentais. Dizia sua irmã: "apesar dos traumas, ela nunca se deixou abater".
Dona Acácia teve a história conjugal atravessada por espancamentos por parte do marido e pela perda trágica de um filho de 18 anos. Esse acontecimento fez o casamento se prolongar por mais 18 anos, contudo, sempre em clima de violência.

\section{Problemas vinculados à dinâmica familiar}

São três casos de mulheres na faixa de 60 e 70 anos com dificuldades nos rearranjos familiares por causa da viuvez e da perda da autonomia. Observam-se, sobretudo, inadequação delas ao novo contexto e ausência de escuta de suas necessidades por parte dos familiares.

Dona Orquídea sempre trabalhou na agricultura ao mesmo tempo em que criava os filhos. Para protegê-la do sofrimento por varizes e outros problemas relacionados ao envelhecimento, o filho a retirou primeiramente da lavoura, depois dos cuidados do galpão onde cuidava dos grãos que colhiam. Finalmente, deixou-a apenas com atividades caseiras. Abalada pela perda do espaço no trabalho e restrita às funções domésticas ela se deprimiu, passou a ter insônia e a tomar medicamentos.

Dona Hortência perdeu uma menina por lúpus aos 18 anos; depois de viúva, apegara-se mais às outras filhas, sentindo-se enciumada pelos relacionamentos delas com os maridos e namorados, revelando dificuldades na individuação. A eclosão repentina de alucinações expressava o conteúdo de seus conflitos, segundo uma nora. Uma voz lhe falava como se fosse o marido já falecido, ameaçando as filhas: "eu sou o seu pai e vim aqui para falar que vocês vão matar a sua mãe".

Dona Iris, do lar, teve uma vida desassossegada, segundo a nora. Mãe de sete filhos, ela perdeu sua própria mãe na infância, um filho ainda bebê e tinha um marido mulherengo do qual se enviuvara. Seu sofrimento se acelerou com a prisão de um filho por tráfico de drogas. Teve que abandonar a casa e morar alternadamente com os filhos e com uma cuidadora. A separação dolorosa das filhas, as perdas por mortes, a dificuldade de se fazer compreender pela família e a situação de ter que se ver amparada por uma cuidadora externa pelas dificuldades dos parentes de entendê-la foram vários elementos que se associaram a seu falecimento por suicídio.

\section{Efeitos de comorbidades}

O impacto de comorbidades e a sua associação com o suicídio 6,11 foram encontrados em mulheres idosas em idades acima dos 70 e 80 anos. Três casos são de agricultoras da Região Sul do país. 
Dona Violeta viu sua autonomia limitada por obesidade, diabetes, colesterol elevado, reumatismo e insuficiência respiratória grave. Temia que o agravamento de suas enfermidades a levassem a perder a mão ou a passar o resto de seus dias numa cadeira de rodas. Viu na morte um ato de coragem para se desvencilhar do sofrimento.

Dona Estrelícia convivia com uma depressão que eclodiu após o falecimento da cunhada e do marido. $\mathrm{O}$ aparecimento dos sintomas de mal de Parkinson a debilitou ainda mais e temia os tremores incontroláveis e as dores difíceis de suportar. A filha comentou que ela se sentia inútil e dizia: “eu não sei por que Deus não leva as pessoas que sofrem".

Dona Camélia, viúva, perdera a filha por câncer de fígado e pulmão e morava com o genro. Ele, já recasado, lhe assegurava os cuidados diários, a convivência com o neto e idas ao clube para distrair-se com as amigas. Ela parecia ter uma vida normal. A confirmação de que tinha um tumor no cérebro e as dores intensas que passou a sentir foram decisivas para o ato de autoextermínio, segundo o genro.

Dona Margarida possuía uma grave surdez de nascença, conseguira se profissionalizar em estatística e trabalhar no serviço público. Lidou com a perda do noivo num acidente traumático, cuidou dos pais até a morte e viu-se abatida na velhice pelo diagnóstico de doença de Alzheimer. Em contraste com os cuidados que proporcionara a sua família, ela insistiu nas tentativas de suicídio até o gesto fatal consumado por atear fogo ao corpo.

Todas essas mulheres encontraram no suicídio a via de escape para evitar o confronto com perdas funcionais, de autonomia ou para fugir de dores, à semelhança do que ocorre com a maioria dos homens idosos que se suicida 7 .

Associação com vários tipos de depressão - a depressão está internacionalmente mais referida entre mulheres idosas que em homens idosos 11,12,15,30,31,32, o que é confirmado em estudos brasileiros 6,33. Ela é um transtorno do humor, de moderado a profundo, de curta ou longa duração, com alterações nos afetos, perda de interesse e prazer pela vida e reduzido nível de energia. Ora se apresenta como depressão secundária reação a uma doença física, trauma psicológico, efeito de drogas de uso contínuo (como o haloperidol) ou reação orgânica a doenças do sistema nervoso (tumor cerebral) - ora como depressão primária - um quadro patológico que independe de fatores externos. Suas causas são orgânicas, ambientais ou circunstanciais: endógenas, relativas à predisposição hereditária; exógenas, relacionadas a fatores ambientais e psicogêni- cas, como reação psicológica desencadeada em resposta a um evento precipitante $30,31,32,33$.

Das 11 mulheres que morreram por suicídio, nove apresentavam casos de depressão, nove de ideação suicida e sete de tentativa de suicídio. Em apenas um, nenhum desses sinais foi descrito, justo na situação de aparecimento de um tumor no cérebro, quadro que pode ter gerado uma depressão exógena pela gravidade da enfermidade.

Dos nove casos, o de Dona Rosa apresentava ocorrência de depressão endógena. Sua história traz uma série de fatos traumáticos contados pelos familiares, ainda que ela não se queixasse deles em nenhum momento de sua vida. Essa senhora ateou fogo ao corpo, carbonizando-se com álcool no quintal de sua casa e morreu sem soltar um gemido ou um grito. Duas histórias evidenciaram apenas duas comorbidades: a de Dona Hortência, uma mulher do lar, "explosiva, geniosa, birrenta e autoritária", segundo o filho, e que sentia ciúme dos relacionamentos das filhas e qualquer coisa a tornava agressiva. Sua depressão e ideação suicida agravaram-se com a eclosão de um surto psicótico agudo de cunho persecutório. Na manhã seguinte, ela se enforcou. E o outro caso é o de Dona Violeta, uma agricultora que sofreu muito com a viuvez, entre outros motivos, porque dependia financeiramente do marido. Após a morte dele, teve de morar com os filhos, perdendo suas referências. Em alguns anos desenvolveu várias comorbidades. Tendo perdido a mãe, uma tia e uma amiga por suicídio, encontrou na morte autoinfligida uma solução para seus males. O medo de ficar inválida foi um motivador importante para a concretização de seu enforcamento.

Sinais evidenciados de depressão, ideação e tentativa apareceram juntos em sete histórias: (1) a de Dona Margarida que se deprimiu após a perda do noivo e da morte dos pais, teve no diagnóstico de doença de Alzheimer o disparador de ideações e várias tentativas de suicídio que por fim se concretizou na morte por chamas; (2) a de Dona Acácia, profissional liberal que não aceitava envelhecer; conviveu com um diagnóstico de transtorno bipolar e ideações suicidas que atravessaram sua vida; suas várias tentativas de morte culminaram com o jogar-se do décimo andar do apartamento onde morava; (3) a de Dona Sépala, considerada sempre deprimida, que manifestou ideações e várias tentativas ao longo do envelhecimento e morreu por enforcamento na própria residência, depois de três meses que o marido que a protegia faleceu; (4) a de Dona Exótica, a agricultora considerada violenta e abusiva que manifestara constantes ideias de se matar, sobretudo depois de perder um irmão por 
suicídio; antes de se enforcar cumpriu o que prometera ao filho: se um dia se fosse, não deixaria nada para a família; quebrou tudo dentro de casa, rasgou os cartões bancários e colocou veneno até nos porcos e burros; (5) a de Dona Orquídea, ligeira e trabalhadora, mas que se deprimiu por ter de se afastar do trabalho agrícola e limitar-se às tarefas domésticas; após ter casado o filho caçula, considerou ter cumprido sua missão e com uma única tentativa, enforcou-se no galpão onde trabalhara; (6) a de Dona Iris que lidou com muitas adversidades familiares durante a vida, mas nos últimos cinco anos conviveu com depressão, transitou pela casa dos vários filhos e no último ano foi deixada aos cuidados de alguém de sua igreja; com histórico de ideações e tentativas, ela se isolou do convívio e se enforcou; e (7) Dona Estrelícia teve uma depressão severa por 12 anos, após ter perdido a cunhada e o marido. Cuidar do filho de uma cunhada a ajudou, mas a eclosão do mal de Parkinson, com tremores e dores, a deixou debilitada e com sensação de que sua vida se tornara inútil. As ideações se intensificaram e fez uma tentativa de suicídio por ingestão de remédios antes de se enforcar na residência.

\section{Perdas e luto por pessoas referenciais}

No conjunto, eram nove viúvas, uma separada e uma solteira, mulheres entre 60 e 82 anos que viveram muitas perdas e mortes. Cinco haviam perdido filhos em circunstâncias traumáticas; três choravam a morte de filhas por doenças graves; e uma lamentava a perda da mãe e da tia por suicídio. Em quatro casos houve a saída involuntária das casas onde as mulheres haviam construído suas trajetórias para viverem agregadas aos filhos, genros e noras. Suas histórias mostram lutos pouco elaborados e sofrimentos silenciados, uma vez que, culturalmente delas se esperaria que fossem as consoladoras e o amparo do grupo familiar em situações difíceis.

\section{Discussão dos dados}

A coorte de mulheres aqui estudadas nasceu numa época histórica que vai do final da década de 1930 aos anos 1950 quando a politização da questão feminista era incipiente no país, e suas histórias, em geral, refletem o papel tradicional que ocuparam na sociedade brasileira. Portanto, as narrativas de suicídio mostram uma condição feminina tradicional. Na maioria, os casos se referem a mulheres do lar (ainda que várias ajudassem os maridos nas lides do campo) dentro de uma perspectiva de subordinação ao homem e responsáveis por serviços domésticos e criação dos filhos. Apenas em dois casos essa situação se diferenciou: o de uma funcionária pública e o outro, de uma profissional liberal. Certamente, as múltiplas razões associadas ao suicídio de mulheres mudarão ao longo do tempo, acompanhando o processo de sua autonomia e liberação.

Em 9 dos 11 casos estudados, as mulheres idosas se suicidaram, após terem vivido a condição feminina, ditada pela cultura patriarcal. Ao dar cabo à própria vida, várias pareciam ter cumprido o destino de gênero 5 e optaram pela morte autoinfligida após terem a certeza de que o haviam executado rigorosamente. A frase: "Agora que meu caçula se casou posso morrer feliz!" dita por uma senhora que meses depois tirou a própria vida, soa como testemunho desse rígido desempenho da função da mulher na relação conjugal e familiar tradicional.

Assim, o lado positivo da condição feminina $8,9,21,22,23,24$, que realça a ética do cuidado, da interação, do convívio, do afeto, da capacidade de viver vários papéis e desempenhá-los simultaneamente serviu a essas mulheres apenas enquanto levaram uma vida mais ativa em relação a suas funções tradicionais de mães, esposas e donas de casa. Na velhice, essa visão funcionou para elas como um sentimento de falta ou como uma sensação de que, por terem servido a vida toda, não deveriam "dar trabalho aos outros".

Os dados evidenciam a relação entre suicídio, tentativas e ideações e aumento do risco. Vários autores 11,12,15,18 apontam um consenso a respeito dessa intrínseca interação. Por exemplo, nos Estados Unidos, existe a relação de 36:1 entre tentativas e efetivação de suicídios de jovens, de 8:1 na população em geral, e entre idosos, de 4:1 12. Constatou-se que não apenas o vínculo entre depressão, ideações e tentativas de suicídio aumenta o risco da morte autoinfligida em idosos, como também a presença concomitante de enfermidades degenerativas, comorbidades e violências. Juntos e somados, esses fatores potencializam a gravidade do quadro, apontando a grande importância de se atentar para os múltiplos riscos em interação.

Muitas das histórias citadas nesta pesquisa secundam o que foi encontrado por vários estudiosos, quanto a condutas que devem servir de alerta aos cuidadores e parentes: descuido com a medicação, colocação em ordem dos pertences ou dos haveres, desinteresse pelas coisas da vida, desinteresse em se cuidar, visitas ao médico com sintomas vagos 11,12,34. Um fato de constatação também internacional 11,12 é que os familiares, somente a posteriori, perceberam que as mulheres que faleceram por suicídio haviam dado várias pistas, dentre elas, tentativas malsucedidas. Existe um mito de que quem ameaça não se 
mata, o que é totalmente errôneo. A posteriori, todos os familiares e próximos às idosas que se suicidaram apontam que elas deram vários sinais e avisos.

Quanto às diferenças de gênero, elas se manifestam em muitos aspectos, especialmente nas vivências e nos sentidos das perdas. Para os homens que faleceram por suicídio e cujas histórias foram ouvidas nesta mesma pesquisa 6,7 , as perdas cruciais que originaram a desistência da vida começaram, geralmente, com a aposentadoria ou com o abandono do trabalho por motivos de saúde. Para a maioria, a inatividade compulsória implicou mudanças radicais de organização do tempo, das entradas financeiras, das relações e do estado social 7. O momento de retirada do cenário público também coincidiu com outras perdas como a viuvez e com o fato de vários deles terem que conviver em casas de filhos ou outros parentes. No caso das mulheres, ressaltam-se as perdas afetivas e do espaço de poder doméstico. Digno de nota é que enquanto todas nove viúvas, cujos casos foram aqui tratados, não se casaram de novo, vários dos homens que faleceram por suicídio ${ }^{6,7}$ estavam com a segunda ou a terceira parceira e alguns eram cuidados por esposas ou ex-esposas. Depois das ausências mais referenciais de sua vida, é como se essas mulheres cumprissem a norma social patriarcalista assinalada por Beauvoir 20, de se tornarem assexuadas e destinadas ao apagamento social. Em resumo, enquanto para os homens a perda do papel profissional ou de provedor foi o que mais influenciou o processo de ruptura de laços com a vida, para as mulheres, pesou muito mais o esfacelamento da função social tradicional que tem no caráter afetivo seu ponto forte: a ausência do companheiro, dos filhos e a perda de poder da autonomia sobre o espaço doméstico.

Uma observação importante é que este estudo, mesmo que muito restrito, desmente as ideias machistas 2,3,4 sobre a inferioridade das mulheres como um fator protetor contra o suicídio. Oito delas se enforcaram - a forca é o meio mais tradicionalmente utilizado tanto por brasileiros quanto por brasileiras para se matar. Em dois casos, as mulheres morreram em chamas, o que constitui uma opção de imolação; e, em um, a mulher se jogou de seu apartamento. Essa última situação já se havia observado como recorrente, num estudo de autópsias psicossociais no Rio de Janeiro 34 . Constatou-se que as várias tentativas feitas por diversas mulheres lhes permitiram uma espécie de treinamento para por em prática seus planos de dar cabo à vida, mostrando o desfecho como um ato pensado e voluntário, frente a situações de intenso sofrimento.
Este estudo evidenciou também que várias mulheres tinham sido medicadas com fármacos antidepressivos. Todavia, a maioria dos familiares não havia sido orientada sobre o uso desses medicamentos e os deixava a cargo da própria idosa. Igualmente, embora recomendado pelas boas práticas de atenção nesses casos, nenhuma das mulheres fazia acompanhamento psicológico. Alguns estudos 11,12 ressaltam que a maioria dos idosos - homens e mulheres - que faleceu por suicídio havia visitado seus médicos antes de se matar, porém essas pessoas falaram apenas vagamente de seus sintomas que, por sua vez, não foram decodificados pelos profissionais.

\section{Conclusões}

Antes de terminar, é importante reconhecer as diversas limitações deste artigo. Uma delas diz respeito à escassa bibliografia, inclusive pouco atualizada, encontrada sobre autópsias psicológicas ou psicossociais especificamente sobre suicídio de mulheres. Outros pontos se referem ao caminho seguido pela pesquisa que deu suporte a este texto. Quando se propôs adotar a expressão autópsias psicossociais (em lugar do conceito de autópsias psicológicas), o intuito foi o de ampliar o contexto diagnóstico que não pode ser reduzido aos problemas psicológicos 28,29. No entanto, existe ainda pouca massa crítica sobre esse tipo de contextualização. Logo, embora se tenha levado em conta a história de vida das mulheres, faltam estudos teóricos e empíricos suficientes sobre os elementos de contexto que devam ser levados em conta e sobre seu peso específico. Por fim, outra limitação é o número pequeno de narrativas de suicídio de mulheres aqui analisado. Tal número, por mais que corresponda à totalidade das histórias ouvidas, é restrito e traz como consequência a impossibilidade de generalização dos achados. Apesar dessas limitações o trabalho permite algumas considerações.

Em síntese, contribuíram para os casos de suicídio doenças degenerativas e comorbidades, violência de gênero e intrafamiliar, engessamento do papel de gênero e perdas referenciais. Esses processos aparecem associados, sobretudo, com depressão como reação ou quadro mórbido, num efeito cumulativo de danos e vulnerabilidades.

Ao contrário de um tipo de literatura 2,3,4 que considera as mulheres ineptas a executarem um plano suicida, os resultados mostram que elas testam métodos e, até clinicamente debilitadas, conseguem ser exitosas em antecipar seu fim.

A questão de gênero é um elemento preditivo das mortes autoinfligidas na velhice. Sua importância não se deve apenas ao fato de as maiores 
taxas de suicídio corresponderem ao grupo masculino no caso brasileiro e mundial. Deve-se também a que existem características que são, em parte, semelhantes e em parte diferentes entre homens e mulheres, já que o peso da socialização se manifesta tanto na vida quanto na morte.

Para os homens, os fatores econômicos e o momento da aposentadoria quando os laços profissionais e relacionais se rompem e o status de poder fora e dentro da família se modifica são de fundamental importância e constituem as bases dos sentimentos de perda e do movimento de dar cabo à vida. Essa situação se acirra com a viuvez. Já para as mulheres, são as perdas afetivas e ambientais e as doenças que as impedem de exercer cuidados para com a família, aquilo que mais está associado às características de suas mortes autoinfligidas.

As diferenças de gênero têm implicações nas estratégias de prevenção. Hoje, a recomendação mais importante para os homens é que se mantenham ocupados. Osgood 35 já argumentava, em 1985, que eles deveriam ter oportunidade de se aposentar depois dos 65, porque a maioria continua capaz e apta em seus campos profissionais. Outros autores 8,9 ressaltam que não é o trabalho nas sim o investimento nas relações, em responsabilidades sociais e o balanceamento entre atividades e relações, a chave de prevenção do suicídio de homens idosos. No caso das mulheres, ajudá-las a desenvolver a autodeterminação e talentos pessoais e derivá-los para fora da famí- lia que talvez não precise mais de seus cuidados, incentivar sua inserção em diversas atividades comunitárias constitui as bases da prevenção primária. É fundamental também uma atitude compreensiva e retributiva dos familiares, cuidando delas quando doentes ou dependentes com o mesmo desvelo com que os trataram, para que não se sintam um peso para filhos e parentes. Quanto à prevenção secundária, tanto para homens como para mulheres, dois fatores parecem cruciais: acostumar-se a pedir ajuda, sem a censura habitual de que estejam incomodando. E, da parte dos cuidadores, a capacidade de oferecer resposta. Ou seja, os familiares ou cuidadores profissionais precisam ser sensíveis aos sinais de pedido de socorro.

Em todas as circunstâncias, o médico é uma figura chave, sobretudo, quando os idosos sofrem de doenças degenerativas ou estão deprimidos. Dado o avanço do envelhecimento populacional é importante educar o médico e os outros profissionais de saúde para que reconheçam os sinais de ideação e planos de dar cabo à vida nos ditos e não ditos dos idosos, capacitando-os a indicar fontes de apoio ou a oferecer ajuda adequada.

Entende-se que conhecer os caminhos que levaram essas idosas a antecipar seu fim só faz sentido se esse conhecimento puder se transformar em pistas e possibilidades de ajuda às que têm ideações e fazem tentativas, ajudando-as a dar novo rumo a sua existência.

\section{Resumen}

Se presentan parte de los resultados de un estudio multicéntrico realizado en Brasil, sobre 51 casos de suicidio de personas mayores (40 de hombres y 11 de mujeres), a través de autopsias psicosociales. Se profundiza en cuestiones sobre la muerte de las 11 mujeres. Se interpretan los datos empíricos a la luz de referenciales clásicos sobre suicidio y género y de reciente literatura nacional e internacional. Los motivos por los que las mujeres se suicidan son, en parte, diferentes a los observados en hombres. Para ellos, el ahorcamiento es el medio principal de suicidio y en ambos sexos se asocian con enfermedades degenerativas y comorbilidades. Las diferencias más importantes, sin embargo, se deben a cuestiones culturales de género, pues los principales factores para suicidio de mujeres son: violencia conyugal e intrafamiliar, pérdidas de personas referenciales y de la función tradicional dentro de la familia, y depresión. Se recomienda atención a los efectos acumulativos de las afecciones en el envejecimiento de las mujeres y las especificidades de la cultura de género.

Suicidio; Identidad de Género; Mujeres; Anciano 


\section{Colaboradores}

M. C. S. Minayo elaborou a concepção do artigo, fez a revisão da literatura, organizou a abordagem metodológica da descrição e análise do material e as conclusões. F. G. Cavalcante participou na revisão da literatura, na descrição e análise do material e na elaboração das conclusões.

\section{Agradecimentos}

A todos os que participaram da pesquisa que deu origem a esse artigo: Raimunda S. Magalhães, Stela Nazareth Meneghel, Denise Machado D. Gutierrez, Marta Conte, Ana Elisa B. Figueiredo, Sonia Grubits, Ana Célia S. Cavalcante, Raimunda M. Mangas, Luiza Jane Eyre S Vieira, Gracyelle A. R. Moreira, Aline G. Trindade, Roger F. Ceccon, Lilian Z. Hesler, Claudia W. Cruz, Regina Sooares, Sanderlei Pereira, Irani Jesus e Girliani S. Souza.

\section{Referências}

1. World Health Organization. Suicide prevention. Geneva: World Health Organization; 2000.

2. Durkheim E. O suicídio. São Paulo: Editora Abril; 1982.

3. Lester D. Suicidal behavior in men and women. Mental Hygiene 1969; 53:340-5.

4. Neuringer C. Suicidal behaviour in women. Crisis 1982; 3:340-8.

5. Meneghel SN, Gutierrez DMD, Silva RM, Grubits S, Hesler LZ, Ceccon RF. Suicídio de idosos sob a perspectiva de gênero. Ciênc Saúde Coletiva 2012; 17:983-92.

6. Cavalcante FG, Minayo MCS. Autópsias psicológicas e psicossociais de idosos que morreram por suicídio no Brasil. Ciênc Saúde Coletiva 2012; 17:1943-54.
7. Minayo MCS, Meneghel SN, Cavalcante FG. Suicídio de homens idosos no Brasil. Ciênc Saúde Coletiva 2012; 17:2665-74.

8. Murphy GE. Why women are less likely than men to committ suicide? Compr Psychiatry 1998; 39:165-75.

9. Canetto SS. Women and suicidal behavior: a cultural analysis. Am J Orthopsychiatry 2008; 78: 259-66.

10. Conwell Y, Thompson C. Suicidal behavior in elders. Psychiatr Clin North Am 2008; 31:333-56.

11. Beeston D. Older people and suicide. Stoke-onTrent: Centre for Ageing and Mental Health, Stanfordshire University; 2006. 
12. Mello-Santos C, Bertolete JM, Wang YP. Epidemiology of suicide in Brazil (1980-2000): characterization of age and gender rates of suicide. Rev Bras Psiquiatr 2005; 27:131-4.

13. Mitty E, Flores S. Suicide in late life. Geriatr Nurs 2008; 29:160-5.

14. De Leo D, Padoani W, Scocco P, Llie D, Bille-Brahe $\mathrm{U}$, Arensman E, et al. Jjelmeland Attenpted and ccompleted suicide older subjects: results from the WHO/EURO Multicentre study of suicidal behavior. Int J Geriatr Psychiatr 2001; 16:300-10.

15. Beautrais AL. Women and suicidal behavior. Crisis 2006; 27:153-6.

16. Pinto LW, Pires TO, Silva CMFP, Assis SG. Evolução temporal da mortalidade por suicídio em pessoas com 60 anos ou mais nos estados brasileiros, 1980 a 2009. Ciênc Saúde Coletiva 2012; 17:1973-81.

17. Milner A, De Leo D. Suicide research and prevention in developing countries in Asia and the Pacific. Bull World Health Organ 2010; 88:795-6.

18. Minayo MCS, Cavalcante FG. Suicídio entre pessoas idosas: revisão da literatura. Rev Saúde Pública 2010; 44:750-7.

19. Beauvoir S. O segundo sexo. São Paulo: Difusão Européia do Livro; 1970

20. Beauvoir S. La vieillesse. Paris: Putman; 1970.

21. Gilligan C. In a different voice: psychological theory and womens development in a different voice. Cambridge: Harvard University Press; 1993.

22. Kristeva J. Crisis of the European subject. New York: Other Press; 2000.

23. Irigaray $L$. Thinking the difference for a peaceful revolution. New York: Routledge; 1994.

24. Cixous H, Cohen K, Cohen P. The laugh of the Medusa. Signs (Chic) 1976; 1:875-93.

25. Ferreira MLR. Mulher como o "outro": filosofia da identidade feminina. In: Ferreira MLR, organizador. O que pensam os filósofos sobre as mulheres. Lisboa: Centro de Filosofia, Universidade de Lisboa; 1988. p. 139-53.
26. Shneidman ES. Autopsy of a suicidal mind. Oxford: Oxford University Press; 2004.

27. Conner KR, Beautrais AL, Brent DA, Conwell Y, Phillips MR, Schneider B. The next generation of psychological autopsy studies: part 2. Intervieww procedures. Suicide Life Threat Behav 2012; 42: 86-103.

28. Minayo MCS, Grubits S, Cavalcante FG. Observar, ouvir, compartilhar: trabalho de campo para autópsias psicossociais. Ciênc Saúde Coletiva 2012; 17:2027-38.

29. Cavalcante FG, Minayo MCS, Meneghel SN, Silva RM, Gutierrez DDM, Conte M, et al. Autópsia psicológica e psicossocial sobre suicídio de idosos: abordagem metodológica. Ciênc Saúde Coletiva 2012; 17:2039-52.

30. Fiske A, Jones RS. Depression. In: Johnson ML, editor. The Cambridge handbook of age and ageing. New York: Cambridge University Press; 2005. p. 246-56.

31. Coser O. Depressão: clínica, crítica e ética. Rio de Janeiro: Editora Fiocruz; 2003.

32. Cole MG, Bellavance F, Mansour A. Prognosis of depression in elderly community and primare care populations: a systematic review and meta-analysis. Am J Psychiatry 1999; 156:1182-9.

33. Cavalcante FG, Minayo MCS, Mangas RMNM. Diferentes faces da depressão no suicídio de idosos. Ciênc Saúde Coletiva; no prelo.

34. Minayo MCS, Cavalcante FG, Mangas RM, Souza JRA. Autópsias psicológicas sobre suicídio em idosos no Rio de Janeiro. Ciênc Saúde Coletiva 2012; 17:2773-81.

35. Osgood NJ. Suicide in the elderly: a practitioners guide to diagnosis and mental health intervention. Rockville: Aspen Systems Corporation; 1985.

Recebido em 08/Mar/2013

Versão final reapresentada em 20/Mai/2013

Aprovado em 25/Jun/2013 